\title{
A Study of Nurses' Stress Management in Facing and Caring for COVID-19 Patients: A Qualitative Content Analysis
}

Mahboobeh Hosseini Moghaddam

Shiraz University of Medical Sciences

\section{Zinat Mohebbi}

Shiraz University of Medical Sciences

Banafsheh Tehranineshat ( $\nabla$ tbanafsheh@yahoo.com )

Shiraz University of Medical Sciences

\section{Research Article}

Keywords: Stress, Management, Nurses, COVID-19

Posted Date: October 26th, 2021

DOl: https://doi.org/10.21203/rs.3.rs-970198/v1

License: (1) This work is licensed under a Creative Commons Attribution 4.0 International License.

Read Full License 


\section{Abstract \\ Background}

Being in the frontline of the battle against COVID-19, nurses need to be capable of stress management to maintain their physical and psychological well-being in the face of a variety of stressors. The present study aims to explore the challenges, strategies, and outcomes of stress management in nurses who face and provide care to COVID-19 patients.

\section{Methods}

The present study is a qualitative descriptive work that was conducted in teaching hospitals affiliated with Shiraz University of Medical Sciences, Iran, from June 2020 to March 2021. Fourteen nurses who were in practice in units assigned to COVID-19 patients were selected via purposeful sampling. Data were collected through semi-structured, individual interviews conducted online. The collected data were analyzed using MAXQDA 10 according to the conventional content analysis method suggested by Graneheim and Lundman.

\section{Results}

The data collected in the interviews resulted in 14 subcategories under 4 main categories: providing care with uncertainty and anxiety, facing psychological and mental tension, creating a context for support, and experiencing personal-professional growth.

\section{Conclusions}

Despite their concern over contracting the infection and transmitting it to their families, nurses feel compelled to provide professional care to patients under all circumstances. Work overload and working in exhausting conditions lead to nurses' physical and psychological burnout, thus their need for the support of authorities and their families. Based on the nurses' experiences, the primary outcomes of caring for COVID-19 patients are personal growth and professional empowerment.

\section{Introduction}

Today, COVID-19 is a life-threatening disease all over the world and has become an international concern and a global emergency [1]. Following the spread of the infection to more than 150 countries and its reaching pandemic proportions, the healthcare personnel, especially nurses, have been in the frontline of providing care to the infected [2]. 
The nature of healthcare professions, nursing in particular, involves working in highly stressful conditions [3]. The results of several studies show that prolonged exposure to stress can cause nurses and other healthcare personnel to suffer such consequences as a reduction in their physical and psychological health, lower job satisfaction, reduced efficiency and quality of care, and an increase in the rate of job burnout $[2,4]$.

The members of healthcare teams, especially nurses, are exposed to many occupational hazards and experience high levels of stress as a result. According to a study, the nurses who cared for severe acute respiratory syndrome (SARS) patients suffered from high levels of psychological distress [5]. At the height of SARS and Middle East respiratory syndrome coronavirus (MERS-CoV) epidemic, nurses and medical students in Taiwan and Saudi Arabia who cared for the infected showed signs of psychological issues, including anxiety, stress and aggressiveness [6]. Fear and anger were other distressful emotions experienced by nurses who provided care to MERS-CoV patients in Saudi Arabia [7].

The results of recent studies show that the healthcare personnel have experienced high levels of anxiety since the outbreak of the COVID-19 pandemic $[1,8]$. According to a study in Iran, the causes of care providers' heightened anxiety in caring for COVID-19 patients are fear of being infected, the difficulty of controlling the pandemic and lack of medical equipment [1]. Stress and the related issues underscore the need for effective psychological hygiene management, psychological well-being and physical health management $[9,10]$. Compared to the other professionals in the healthcare system, nurses spend more time with patients and play a key role in controlling and treating emerging diseases [11]. Accordingly, it is necessary to evaluate nurses' mental health and stress management skills in facing and caring for COVID-19 patients and to identify barriers to their stress management during the current pandemic. Considering the above-mentioned points and the fact that the researchers could not find any studies which investigated nurses' stress management at the height of the COVID-19 pandemic, a qualitative study could provide an in-depth understanding of the subject in question. Accordingly, the present study uses a qualitative approach to explore the challenges, strategies, and outcomes of stress management in nurses who face and provide care to COVID-19 patients.

\section{Materials And Methods}

The present study is a qualitative descriptive work of research with a content analysis design which was conducted from June 2020 to March 2021 in teaching hospitals affiliated with Shiraz University of Medical Sciences. In total, 14 nurses who were in practice in special care, internal, surgical and emergency departments were selected via purposeful sampling [12]. Sampling continued until the data was saturated, i.e. no new knowledge could be obtained and the categories were saturated in terms of characteristics and dimensions. The inclusion criteria were: having a bachelor's degree in nursing, having worked for at least six months in a clinical unit, providing direct care to patients with COVID-19, and being willing to participate in the study. The subjects who were not willing to be interviewed or continue their participation in the study were excluded. 
Data were collected through 14 in-depth, semi-structured, individual interviews which were conducted by the third author. The participants were interviewed by video calls with "WhatsApp", in workplace (one of the classes at school of nursing and midwifery), after arrangements about the time of the interviews had been made with them. Each interview lasted from 40 to 60 minutes and began with a general question: "Can you describe your experiences of a work shift in which you faced or cared for a COVID-19 patient?" Subsequently, the interviewer asked more specific questions: "What are your experiences of the challenges and barriers to stress management when you faced and cared for COVID-19 patients?", "What factors improve stress management when nurses face and care for COVID-19 patients?", "What factors undermine stress management when nurses face and care for COVID-19 patients?", "How did you feel when/if you could not manage your stress when you faced and cared for COVID-19 patients?", "What stress management strategies can help nurses who face and care for COVID-19 patients?" and "What are the outcomes of stress management for nurses who face and care for COVID-19 patients?" Moreover, follow-up questions were asked to obtain more details about the objective of the study. The participants' voices were recorded using a Sony Voice Recorder ICD-TX650.

The present study used the conventional content analysis method suggested by Graneheim and Lundman (2004). Frequently used in studies related to nursing, this method allows for collecting new, rich information and mental analysis of the content of textual data through systematic categorization, codification and theme making or developing known paradigms $[13,14]$. Each interview was transcribed in full at the first possible chance after it was completed. To immerse in the data and obtain a general idea of the participants' answers, the researchers read the transcripts several times. Words, phrases and paragraphs which carried significance with regard to the challenges, strategies and outcomes of stress management in the COVID-19 crisis were selected as meaning units. Similar initial codes were classified into broader categories based on their similarities and differences and categories were thus developed. To ensure that the codes were consistent, the researchers reviewed the categories and compared them to the data again. Afterward, through deep and accurate contemplation and comparison of the categories against each other, the themes emerged [15]. The data were organized using MAXQDA 2010 distributed by VERBI.

The trustworthiness of the collected data was ensured using Lincoln and Guba's criteria [16]. Credibility was achieved through prolonged engagement with the data, member checking, peer debriefing, maximum variation sampling, and searching for contrasting evidence. To ensure dependability and confirmability, the researchers relied on audit trial which consists of using proper techniques to conduct interviews, making accurate transcripts and having the data reviewed by one's co-researchers. To enhance the transferability of the results, the researchers provided accurate and thorough descriptions of the subject under study, the participants' characteristic, methods of data collection and analysis, along with documented examples of the participants' statements [17].

\section{Results}


The participants' ages ranged from 28 to 47 years, with the mean being 34.1 years. The majority of the participants were female (Table 1). Analyses of the data resulted in 510 initial codes, 14 subcategories and four main categories, namely: providing care with uncertainty and anxiety, facing psychological and mental tension, creating a context for support, and experiencing personal-professional growth (Table 2).

Providing care with uncertainty and anxiety and facing psychological and mental tension were the challenges which the nurses in the present study experienced when they faced and cared for patients with COVID-19.

\section{Providing care with uncertainty and anxiety}

One of the findings of the present study was providing care with uncertainty and anxiety. This category consisted of the subcategories of providing care as a professional duty, concern over transmitting the infection to one's family, fear of the unknown aspects of the disease, and concern over making wrong decisions.

\subsection{Providing care as a professional duty}

According to the participants' experiences, despite a lack of facilities and personal protective equipment, there was a dominant sense of commitment among nurses to perform their professional duties in the COVID-19 pandemic. From the nurses' point of view, working in difficult and dangerous conditions is part of a nurse's job which must be maintained during the pandemic of an emerging disease.

“... anyway, it's my job to give care in all circumstances and I had to do it at that time ..." (P1).

\subsection{Concern over transmitting the infection to one's family}

Despite their commitment to perform their professional duties, the nurses in the present study were worried about transmitting the infection to their families and their concern acted as a barrier to their stress management. The participants also mentioned that when their colleagues were infected, the fear of contracting the disease in the near future was a barrier to their stress management.

"... I was really worried that I could be the source of infection to my 60-year-old parents ..." (P6).

\subsection{Fear of the unknown aspects of the disease}

One of the major barriers to stress management in the face of COVID-19 was lack of knowledge about the nature of the infection. Fear of the personnel arising from the unknown aspects of the disease was a main source of stress.

“... We didn't know anything about it. The disease was completely unknown to us ..." (P 3).

\subsection{Concern over making wrong decisions}


Some of the nurses were working in COVID-19 units voluntarily; however, they admitted that they had felt doubtful about their decision to provide voluntary care to COVID-19 patients in the first few days.

“... I kept wondering if my decision was right or not ..." (P 4).

Another nurse stated that:

"Maybe the decision I made was a step to fulfill my personal commitment ..."(P 2).

\section{Facing psychological and mental tension}

Many of the nurses who were working in COVID-19 units declared that they had experienced a variety of psychological issues during their practice in these units which prevented them from managing their stress. This category consisted of the sub-categories of families' insistence on quitting one's job, working in difficult conditions, lack of personal protective equipment, and feeling rejected.

\subsection{Families' insistence on quitting one's job}

One of the sources of psychological tension for the nurses was the insistence of some of their family members that they should quit their profession as nurses during the pandemic.

"My dad was strongly against me staying in this profession at those critical times ..." (P 3).

\subsection{Working in difficult conditions}

Many of the participants described working in personal protective gear as very difficult. They also referred to work fatigue and physical exhaustion due to work overload as barriers to stress management.

"When your shift is over, you can barely breathe; with a high PaCO2, it's hard to breathe ... it's hard to eat in this coverall, you can't drink any water through your shift ... the fatigue .... Working in such conditions won't let you manage stress" (P 12).

\subsection{Lack of personal protective equipment}

The participants stated that one of the major barriers to stress management was lack of personal protective equipment and coveralls, especially in the first few days of the pandemic. According to one of the nurses:

"When the epidemic started, we didn't have access to special gear for COVID-19 protection and had to care for the infected with minimum equipment, in regular masks and uniforms ..." (P 5).

\subsection{Feeling rejected}

Another barrier to stress management in COVID-19 units was being treated inappropriately and rejected by the personnel in non-COVID-19 units. One of the participating nurses stated that: 
"When I got on the hospital shuttle, I felt so nervous. All the other staff that didn't work in COVID-19 units would protest and tell the driver that he shouldn't let me get on board ... I should get off ...." (P 7).

Some of the participants had experienced rejection by their family members and relatives, which made it more difficult for them to manage stress.

"Once, when one of my relatives saw me, she took her son's hand and walked away from me ..." (P 3).

\section{Creating a context of support}

In the present study, the participants believed that creating a context of support is an important stress management strategy in facing and caring for COVID-19 patients. This category consists of the subcategories of proper intradepartmental management, support of the authorities, and effective communication skills.

\subsection{Proper intradepartmental management}

The participants' experiences showed that proper intradepartmental management, e.g. planning according to the personnel's conditions, replacing COVID-19 personnel with volunteers, avoiding discrimination, playing soft music in the units, and using effective interpersonal communication skills, including empathy, humor and spreading positive thinking, can contribute to the personnel's stress management. During the COVID-19 crisis, the unit managers tried to make plans according to the personnel's conditions in order to reduce the personnel's stress.

"The husband of one of my staff here could spend two weeks a month with his wife .... I arranged her shifts so she didn't have to work or worked less when her husband was with her so she wouldn't be so worried about infecting her husband ..." (P 1).

To reduce nurses' direct contact with COVID-19 patients, the unit managers put the overstressed nurses in charge of recording patients' history in their files in order to reduce stress in them.

"One of my staff was stressed out .... I made her the shift supervisor so she would be busy with the patients' files and have less direct contact with the patients ..." (P 8).

\subsection{Support of the authorities}

In order to support the nurses by helping them manage their stress, the unit and hospital authorities arranged certain hours for the nurses to meet with the hospital counselor or for the counselor to see the nurses.

"Whenever the personnel felt they were suffering from psychological tension and needed counseling, they could visit the hospital counselors ...." (P 11). 
Another strategy used by the authorities to help the nurses manage their stress was setting up workshops to inform the nurses about the pathophysiology of COVID-19, how the infection is transmitted, the correct use of personal protective equipment, and regimens that boost the immune system. This information proved very influential in reducing stress in the nurses.

"We didn't have any preparation from before; education is really important; once we learned more about the disease, we could protect ourselves better .... We were less stressed ..." (P 12).

According to the participants, continuing education was integral to enabling them to manage the stress caused by being in contact with COVID-19 patients. Even though the presence of the supervisors and the other members of the treatment team in the environment could communicate a sense of support and hope to the nurses, some of the supervisors refused to be present in the places where the patients were being cared for.

"Our supervisor won't even enter the unit to see for herself what kind of issues we are dealing with here ..." (P 9).

\subsection{Effective communication skills}

The head nurses' use of effective communication skills in their interactions with the staff was found to be a successful approach to stress management in those critical times. In addition, through empathy, the unit personnel tried to connect to their colleagues' inner worlds and have a mutual understanding of their emotions and concerns, thereby coping with the stress caused by the COVID-19 crisis. The participants stated that in an empathetic relationship, they could experience a sense of support.

Showing appreciation and giving rewards were found to be effective stress management strategies which could raise the personnel's spirits and improve interpersonal relationships. According to one of the participants:

"One of the main issues for the nurses who are doing a good job in these units is not receiving any appreciation or rewards. There is a limit to any person's tolerance. Some turn to spirituality for strength, but not everyone is spiritual. In short, there is a lack of appreciation ..." (P 5).

Other behaviors which contributed to the nurses' stress management were exchanging friendly banters with each other, spreading positive thinking, and remaining optimistic about the future.

\section{Experiencing personal-professional growth}

The participants referred to experiencing personal-professional growth as one of the outcomes of working in the very difficult conditions created by the spread of COVID-19. Caring for COVID-19 patients was a constructive experience which could prove instrumental in coping with problems in the future. Making an effort to use various stress management skills in the face of COVID-19 improved nurses' empowerment and gave them a chance for personal growth. Compared to the time before the emergence 
of COVID-19, nurses can focus on their problems better and manage stress and stressors more effectively. This category consists of the subcategories of improved learning, perception of positive feelings at the end of a crisis, and self-transformation.

\subsection{Improved learning}

The participants believed that, despite all the difficulties, working during the pandemic had resulted in their gaining useful knowledge. Their experiences showed that providing care during the COVID-19 pandemic had helped them develop time management skills, learn to make optimal use of the available equipment and deal with deficiencies, improve their medication knowledge, increase their knowledge of emerging diseases, and learn to make effective use of infection control strategies.

"I had read a few things about emerging diseases, but working in this pandemic has given me the chance to gain hands-on experience of caring for these patients ..." (P 7).

\subsection{Perception of positive feelings at the end of a crisis}

While providing care to COVID-19 patients, the participants had experienced such positive feelings and emotions as elevated self-confidence, personal satisfaction, the opportunity to prove their competence, and the good feeling of overcoming the difficulties and challenges of caring for COVID-19 patients.

"Working in these conditions created a positive sense of being useful to others in me ... which made me feel happy and lively and physical fatigue could not take away my happiness ..." (P 6).

Many of the participants mentioned feeling good about solving problems and happiness about serving one's fellowmen to be among other outcomes of working in the COVID-19 crisis.

"Having been put on the path to serve my fellowmen was the positive feeling that I experienced ..." (P 4).

Another participant stated:

"I feel happy now that I could live through the problems I had at the time ..." (P 12).

\subsection{Self-transformation}

The results of the study showed that the experience of caring for COVID-19 patients in difficult conditions had strengthened relationships between colleagues and between friends at work. Many of the participants had come to have higher regard for the meaning and value of their lives and what they had. The participants compared working in the COVID-19 crisis to fighting in a war which had transformed them by making them braver in the face of critical conditions and more empowered in managing difficult times.

"Working during the current pandemic has helped me discover my abilities .... Now I know how to act in war conditions ..." (P 7). 


\section{Discussion}

The present study was conducted to identify the challenges, strategies and outcomes of stress management for nurses who come into contact with and provide care to COVID-19 patients. Analyses of the collected data showed that the nurses' experiences could be classified into four categories: providing care with uncertainty and anxiety, facing psychological and mental tension, creating a context for support, and experiencing personal-professional growth.

One of the findings of the present study was nurses' feelings of uncertainty and anxiety in providing care. The nurses were worried about transmitting the infection to their family members, were not adequately aware of the nature of the disease, and were in fear of making wrong decisions about caring for COVID19 patients; yet, they deemed it their professional duty to provide care to those patients. In another study, the nurses were worried about facing patients with COVID-19, contracting the infection and transmitting it to their loved ones. The nurses were also concerned about the unknown aspects of the disease and its potentially dangerous nature, uncertainty about the end of the pandemic, and the impact of the pandemic on their job security and other working conditions [18]. Another study reported that the healthcare personnel suffered psychosocial issues, e.g. depression, anxiety, and stress, as a result of having inadequate knowledge about COVID-19, continuously caring for the infected, work overload, frequent exposure to distressful events, such as death, and fear of infecting their families [19]. In yet another study, the nurses suffered from stress due to caring for the infected and work overload, which resulted in their experiencing burnout, emotional fatigue, and despair [20]. Measures such as workshops and counseling with a psychologist should be taken to decrease stress and anxiety in nurses who are directly involved in caring for COVID-19 patients as prolonged anxiety can lead to psychological distress, depression and other psychological issues.

Another finding of the present study was nurses' exposure to mental and psychological tension which originated from the insistence of their families that they should quit their jobs, feeling rejected, witnessing the death of their colleagues and friends, fear of infecting their families, lack of medical equipment, and fatigue. According to one study, the major contributory factors in the psychological pain of nurses, doctors, therapists and other healthcare professionals were the emotional efforts and physical fatigue that they experienced in caring for COVID-19 patients whose conditions were deteriorating quickly. Seeing and caring for colleagues who were severely infected or lost their lives to COVID-19, lack of ventilators and other medical equipment needed to care for patients in critical conditions, and anxiety due to new clinical roles and work overload were other causes of psychological distress [21].

As a result of social stigmatization, the nurses suffered from social dejection and loneliness. They preferred to be isolated because they were afraid that they might transmit the infection to others [22]. Another study reported that frequent changes in the hospital policies, routines, and guidelines which were updated confused the nurses [23]. In another study, the participants reported work overload as a result of lack of medical protective equipment: the nurse managers had to reduce the number of care providers to ensure that all the personnel had access to protective equipment by conserving it. Moreover, to avoid 
going to break rooms during working hours, the healthcare professionals did not eat anything, and they experienced severe emotional distress and grief if their patients passed away [24]. During the COVID-19 pandemic, nurses were exposed to so many psychological issues that they sometimes had to resign. Thus, support interventions, including informing the public about the pandemic and self-quarantine, providing enough resources to meet the basic needs of nurses in quarantine, and giving nurses easy access to social media so that they can be in touch with their friends and families can encourage nurses to stay in their jobs [22]. Also, counseling the personnel and preparing them for the challenges in their profession and giving a clear picture of what they are going to face can prove helpful [25]. Educational programs about death anxiety can result in better nursing care in critical situations. Educational workshops are effective in reducing death anxiety [26]. Giving nurses active guidance and motivating them to achieve psychological growth during the pandemic can contribute to their psychological adaptation [27].

Another finding of the present study was the role of creating a context of support. The participants' experiences showed that intradepartmental management, support of the authorities, and effective communication skills are effective ways to support nurses in the stressful conditions caused by the pandemic. A context of support will reduce nurses' anxiety and help them continue to provide quality healthcare services in the crisis. According to one study, personal resilience protects nurses from anxiety by enabling them to adapt to irritating, stressful conditions. In addition, public support for nurses plays a significant role in their achieving positive emotional states in stressful times, such as the outbreak of a disease [28]. In another study, the nurses practiced self-isolation as a protection strategy [23]. The nurses believed that one of the greatest challenges in their workplace during the pandemic was lack of a crisis management plan on the management and ministry of healthcare levels [29].

The experiences of the nurses and doctors in another study showed that one way to prevent the physical and emotional exhaustion caused by working in special care units is using educational interventions to develop resilience in the personnel. Also, regular and systematic educational programs designed to improve the healthcare personnel's preparation and efficacy in crisis management seemed essential. Healthcare professionals were also found to rely on self-management mechanisms. They preferred to focus on their work rather than listen to rumors about COVID-19. Some of the other personnel engaged in relaxation activities, including seeing movies, taking showers, and reading. They also stressed the significance of good nutrition and adequate rest and sleep [24].

Moreover, stress management approaches, including relaxation, biofeedback, cognitive strategies, interventions focused on eliminating or decreasing stressful working conditions, such as job redefinition and clear job description, formation of joint personnel committees, and increasing the personnel's participation in organizational decisions are essential to controlling stressful conditions [30]. One support strategy for the personnel in the frontline of caring for patients with COVID-19 is providing them with online psychological support services which enable the personnel to express their needs. Access to mental health care is possible through telemedicine managed by mental health experts, mobile phone applications, online sources, and virtual peer support. Online psychological care networks are useful in 
dealing with the stress and concerns of healthcare professionals and their families and relatives and other individuals [31]. One study classifies nurse managers' experiences of management of the nursing workforce during the COVID-19 crisis into management of workforce recruitment (volunteers and nonvolunteers) and management of workforce (via motivational measures and psychological support). Successful crisis management depends on using flexible and situation-based principles of management toward recruiting adequate workforce and retaining the current workforce [32]. Providing a supportive environment through crisis management training, providing adequate equipment and manpower, and developing resilience skills in staff helps nurses manage stress.

Another finding of the present study was the nurses' experiencing personal and professional growth. This theme consisted of the subcategories of improved learning, perception of positive feelings at the end of a crisis, and self-transformation. According to a study, one of the psychological experiences of the nurses who cared for COVID-19 patients was perception of growth under pressure and appreciation of life. The nurses declared that, in the pandemic, the picture of the nursing profession had improved, nurses had realized their potential, and nurses' ability to cope with difficulties in life had elevated [27]. Another study reported an increase in nurses' self- esteem and sense of responsibility during the pandemic [24]. One of the significant experiences of new nurses was learning during the pandemic. The nurses stated that caring for COVID-19 patients gave them a chance to develop their clinical skills, gain hands-on clinical experience, and learn how to adapt to critical conditions. They also learned methods of protecting themselves, using the equipment needed in caring for COVID-19 patients, time management, and providing care in the shortest possible time to minimize contact with the infected [33]. Another study reported an increase in nurses' awareness about the value of the nursing profession and their sense of achievement and pride. Moreover, the nurses had a better perception of their professional and social identity and established stronger relationships with their colleagues. Many of the nurses had a greater appreciation of life and everything which they had. The pandemic had given them a chance to realize their full potential, which, in turn, increased their self-confidence. In addition, by self-reflection, the nurses discovered their weaknesses and tried to develop their knowledge and skills. They appreciated the support of their friends, colleagues and the society and developed a more positive perspective on the significance of life and family health [34].The results of studies show that projecting a positive image of the nursing profession in the society helps nurses find their potential, improves nurses' professional knowledge and skills in the epidemic of emerging diseases, and increases nurses' awareness of their personal and professional growth and professional identity by extension.

As the main strength of this study, we conducted one of the qualitative studies that explored strategies and outcomes of stress management based on experiences of the nurses who provide directly care to COVID-19 patients. One of the limitations of the present study was the fact that, because of the COVID-19 pandemic, the interviews were not conducted on a face-to-face basis. However, the researchers tried to have a better interaction with the participants by making video calls to them. Another limitation of the study was that the interviews were conducted individually. Focus group interviews allow for the collection of richer information. 


\section{Conclusion}

Despite the fact that the nurses in the present study regarded caring for COVID-19 patients as their professional duty, they needed the support of their superiors, families, and friends. Authorities can create an effective context of support through proper intradepartmental management, providing adequate equipment, giving positive feedback, and organizing continuing workshops. In addition, effective communication skills, receiving positive feedback and easy access to counselors can contribute to nurses' stress management and adaptation. The outcomes of stress management on the part of nurses were found to include understanding the meaning of life and experiencing personal and professional growth. It is suggested that future studies address the causes of barriers to nurses' stress management in the COVID-19 crisis and the strengths and weaknesses of the healthcare system in dealing with this pandemic.

\section{Abbreviations}

COVID-19: Coronavirus infection disease-19

SARS: Severe Acute Respiratory Syndrome

MERS-CoV: Middle East respiratory syndrome coronavirus

\section{Declarations}

\section{Ethics approval and consent to participate}

This study was conducted in accordance with the World Medical Association's Declaration of Helsinki. The present study was approved by the ethics committee of Shiraz University of Medical Sciences and registered at IR.SUMS.REC.1399.416. The study materials (interview questions and informed consent form) were approved by the ethics committee of the university. Before the interviews, the participants were informed by phone about the objective of the study, the voluntary basis of participation, the methods of data collection and the reason for recording the interviews. Also, the role of the researchers and the participants, and the confidentiality and anonymity of information were explained. Then the subjects who were willing to participate were asked to complete the informed consent form by Porsline. All participants provided informed written consent at the time of the interview about publication of identifying information in an online open-access publication. The participants were also informed that they were free to withdraw from the study at any point.

\section{Consent for publication}

Not applicable.

\section{Availability of data and material}


The dataset generated and/or analysed during the current study are not publicly available due to promises of participant anonymity and confidentiality but are available from the corresponding author on reasonable request.

\section{Competing interests}

The author(s) declared no potential conflicts of interest for the research, authorship, and/or publication of this article.

\section{Funding}

The author(s) received no financial support for the research, authorship, and/or publication of this article.

\section{Authors' contributions}

${ }^{1} \mathrm{MHM}$ has made a substantial contribution to the study design, analysis, interpretation of data, and revised the article critically. ${ }^{2}$ ZM has made a substantial contribution to the concept, design, data analysis, interpretation of data, revised the article critically and approved the version to be published. ${ }^{3}$ BT is responsible for the acquisition of data, study design, analysis, interpretation of data, drafted, and revised the article critically and approved the version to be published.

\section{Acknowledgements}

The present article is the result of a research project registered at Shiraz University of Medical Sciences (no.19757). The authors would like to thank the authorities and nurses of the hospitals affiliated with Shiraz University of Medical Sciences who participated in the study.

\section{References}

1. Khoshnood Z, Mehdipour-Rabori R, Nazari Robati F, Helal Birjandi M, Bagherian S. Patients' Experiences of Living with Coronavirus Disease 2019: A Qualitative Study. Evidence Based Care. 2021 1;11(1):44-50. Doi: 10.22038/EBCJ.2021.57471.2499

2. Fathi Ashtiani A, Pirzadi H, Shokoohi-Yekta M, Tavallai S. The influence of teaching program of stress management and communication skills on improvement of mental health of nurses and hospital staff: an experimental study. Iran Journal of Nursing. 2014;27(90):1-13. Doi: 10.29252/ijn.27.90.91.1

3. Rose S, Hartnett J, Pillai S. Healthcare worker's emotions, perceived stressors and coping mechanisms during the COVID-19 pandemic. PloS one. 2021, 9;16(7): e0254252. https://doi.org/10.1371/journal.pone.0254252

4. Stathopoulou H, Karanikola MN, Panagiotopoulou F,Papathanassoglou ED. Anxiety levels and related symptoms in emergency nursing personnel in Greece. Journal of Emergency Nursing. 2011;37(4):314-20. DOI: 10.1016/j.jen.2010.03.006 
5. Park J-S, Lee E-H, Park N-R, Choi YH. Mental health of nurses working at a government-designated hospital during a MERS-CoV outbreak: a cross-sectional study. Archives of psychiatric nursing. 2018;32(1):2-6. DOI: 10.1016/j.apnu.2017.09.006

6. Al-Rabiaah A, Temsah M-H, Al-Eyadhy AA, Hasan GM, Al-Zamil F, Al-Subaie S, et al. Middle East Respiratory Syndrome-Corona Virus (MERS-CoV) associated stress among medical students at a university teaching hospital in Saudi Arabia. Journal of infection and public health. 2020;13(5):68791. doi: 10.1016/j.jiph.2020.01.005.

7. Abolfotouh MA, AlQarni AA, Al-Ghamdi SM, Salam M, Al-Assiri MH, Balkhy HH. An assessment of the level of concern among hospital-based health-care workers regarding MERS outbreaks in Saudi Arabia. BMC infectious diseases. 2017;17(1):1-10. DOI: https://doi.org/10.1186/s12879-016-2096-8

8. Zhou P, Yang X-L, Wang X-G, Hu B, Zhang L, Zhang W, et al. A pneumonia outbreak associated with a new coronavirus of probable bat origin. nature. 2020;579(7798):270-3. doi: 10.1038/s41586-0202012-7

9. Kravits K, McAllister-Black R, Grant M, Kirk C. Self-care strategies for nurses: A psycho-educational intervention for stress reduction and the prevention of burnout. Applied Nursing Research. 2010;23(3):130-8. doi: 10.1016/j.apnr.2008.08.002.

10. Organization WH. Mental healthand psychosocial considerations during the COVID-19 outbreak, 18, 2020. World Health Organization, 2020.URL: https://www.who.int/docs/defaultsource/coronaviruse/mental-health-considerations.pdf

11. Abbaszadeh A, Ehsani SR. Nurse 'Perceptions of Caring of Emerging Avian Influenza Disease. Nursing And Midwifery Journal. 2015;12(11):973-81. URL: http://unmf.umsu.ac.ir/article-1-1787en.html

12. Holloway I, Galvin K. Qualitative research in nursing and healthcare: John Wiley \& Sons; 2016.

13. Elo $S$, Kyngäs $H$. The qualitative content analysis process. Journal of advanced nursing. 2008;62(1):107-15. doi: 10.1111/j.1365-2648.2007.04569.x.

14. Krippendorff K. Content analysis: An introduction to its methodology: Sage publications; 2018.

15. Graneheim UH, Lundman B. Qualitative content analysis in nursing research: concepts, procedures and measures to achieve trustworthiness. Nurse education today. 2004;24(2):105-12. doi: 10.1016/j.nedt.2003.10.001.

16. Burns N, Grove SK. Understanding nursing research-eBook: Building an evidence-based practice: Elsevier Health Sciences; 2010.

17. Speziale HS, Streubert HJ, Carpenter DR. Qualitative research in nursing: Advancing the humanistic imperative: Lippincott Williams \& Wilkins; 2011.

18. Arnetz JE, Goetz CM, Arnetz BB, Arble E. Nurse reports of stressful situations during the COVID-19 pandemic: qualitative analysis of survey responses. International Journal of Environmental Research and Public Health. 2020;17(21):8126. doi: 10.3390/ijerph17218126.

19. Carbajal $A B$, Boluarte AS, Boluarte AR, Soto $C M$. Working conditions and emotional impact in healthcare workers during COVID-19 pandemic. Journal of Healthcare Quality Research. 2020. doi: 
10.1016/j.jhqr.2020.08.002

20. Ali H, Astin Cole AA, Sa'd Hamasha GP. Major Stressors and Coping Strategies of Frontline Nursing Staff During the Outbreak of Coronavirus Disease 2020 (COVID-19) in Alabama. Journal of Multidisciplinary Healthcare. 2020;13:2057. doi: 10.2147/JMDH.S285933

21. Ayanian JZ, editor Mental health needs of health care workers providing frontline COVID-19 care. JAMA Health Forum; 2020: American Medical Association. doi:10.1001/jamahealthforum.2020.0397

22. Kackin O, Ciydem E, Aci OS, Kutlu FY. Experiences and psychosocial problems of nurses caring for patients diagnosed with COVID-19 in Turkey: A qualitative study. International Journal of Social Psychiatry. 2020: doi: 10.1177/0020764020942788

23. Lam KK, Hung SYM. Perceptions of emergency nurses during the human swine influenza outbreak: A qualitative study. International emergency nursing. 2013;21(4):240-6.

DOI:10.1016/j.ienj.2012.08.008

24. Liu Q, Luo D, Haase JE, Guo Q, Wang XQ, Liu S, et al. The experiences of health-care providers during the COVID-19 crisis in China: a qualitative study. The Lancet Global Health. 2020;8(6):e790-e8. doi: 10.1016/S2214-109X(20)30204-7

25. Chandra A, Vanjare $H$. Coping by the healthcare workers during COVID-19 pandemic in developing countries-A review. Anaesthesia, Pain \& Intensive Care. 2020;24(3):346-53.URL:

https://search.bvsalud.org/global-literature-on-novel-coronavirus-2019-ncov/resource/en/covidwho823510

26. Galehdar N, Kamran A, Toulabi T, Heydari H. Exploring nurses' experiences of psychological distress during care of patients with COVID-19: a qualitative study. BMC psychiatry. 2020;20(1):1-9. DOI:https://doi.org/10.1186/s12888-020-02898-1

27. Sun N, Wei L, Shi S, Jiao D, Song R, Ma L, et al. A qualitative study on the psychological experience of caregivers of COVID-19 patients. American journal of infection control. 2020;48(6):592-8. doi: 10.1016/j.ajic.2020.03.018

28. Labrague LJ, De los Santos JAA. COVID-19 anxiety among front-line nurses: Predictive role of organisational support, personal resilience and social support. Journal of nursing management. 2020;28(7):1653-61. doi: 10.1111/jonm.13121.

29. Koh Y, Hegney D, Drury V. Nurses' perceptions of risk from emerging respiratory infectious diseases: a Singapore study. International journal of nursing practice. 2012;18(2):195-204. doi: 10.1111/j.1440172X.2012.02018.x.

30. Roberts RK, Grubb PL. The consequences of nursing stress and need for integrated solutions. Rehabilitation Nursing. 2014;39(2):62-9. doi: 10.1002/rnj.97

31. Teixeira CFdS, Soares CM, Souza EA, Lisboa ES, Pinto ICdM, Andrade LRd, et al. The health of healthcare professionals coping with the Covid-19 pandemic. Ciência \& Saúde Coletiva. 2020;25:3465-74. DOI: 10.1590/1413-81232020259.19562020

32. Poortaghi S, Shahmari M, Ghobadi A. Exploring nursing managers' perceptions of nursing workforce management during the outbreak of COVID-19: a content analysis study. BMC nursing. 
2021;20(1):1-10. DOI https://doi.org/10.1186/s12912-021-00546-x

33. Casafont C, Fabrellas N, Rivera P, Olivé-Ferrer MC, Querol E, Venturas $M$, et al. Experiences of nursing students as healthcare aid during the COVID-19 pandemic in Spain: A phemonenological research study. Nurse Education Today. 2021;97:104711. Doi: 10.1016/j.nedt.2020.104711.

34. Cui S, Zhang L, Yan H, Shi Q, Jiang Y, Wang Q, et al. Experiences and Psychological Adjustments of Nurses Who Voluntarily Supported COVID-19 Patients in Hubei Province, China. Psychology Research and Behavior Management. 2020;13:1135. DOI https://doi.org/10.2147/PRBM.S283876

\section{Tables}

Table 1 The demographic characteristics of the participants

\begin{tabular}{|c|c|c|c|c|c|c|}
\hline Participants & Age & Gender & $\begin{array}{l}\text { Marital } \\
\text { Status }\end{array}$ & Position & $\begin{array}{l}\text { Work } \\
\text { experience }\end{array}$ & Ward \\
\hline P1 & 35 & Female & Married & $\begin{array}{l}\text { Head } \\
\text { nurse }\end{array}$ & 12 & ICU \\
\hline P2 & 36 & Female & Single & Staff nurse & 10 & Internal \\
\hline P3 & 31 & Female & Single & Staff nurse & 9 & ICU \\
\hline P4 & 29 & Female & Single & Staff nurse & 4 & ICU \\
\hline P5 & 25 & Male & Single & Staff nurse & 22 & ICU \\
\hline P6 & 37 & Female & Married & Staff nurse & 12 & ICU \\
\hline P7 & 35 & Female & Single & Staff nurse & 11 & $\begin{array}{l}\text { Thorax } \\
\text { Surgery }\end{array}$ \\
\hline P8 & 47 & Female & Married & $\begin{array}{l}\text { Head } \\
\text { nurse }\end{array}$ & 20 & $\begin{array}{l}\text { Thorax } \\
\text { Surgery }\end{array}$ \\
\hline P9 & 30 & Male & Single & Staff nurse & 8 & Emergency \\
\hline P10 & 29 & Female & Married & Staff nurse & 7 & Emergency \\
\hline P11 & 45 & Female & Married & Staff nurse & 18 & Internal \\
\hline P12 & 38 & Female & Single & Staff nurse & 9 & ICU \\
\hline P13 & 28 & Female & Single & Staff nurse & 5 & ICU \\
\hline P14 & 34 & Male & Married & Staff nurse & 6 & $\begin{array}{l}\text { Thorax } \\
\text { Surgery }\end{array}$ \\
\hline
\end{tabular}


Table 2 The categories and sub-categories of this study

\begin{tabular}{|c|c|}
\hline Categories & Sub-categories \\
\hline \multirow{5}{*}{ Providing care with uncertainty and anxiety } & Providing care as a professional duty \\
\hline & Concern over transmitting the infection to one's family \\
\hline & Fear of the unknown aspects of the disease \\
\hline & Concern over making wrong decisions \\
\hline & Families' insistence on quitting one's job \\
\hline \multirow{3}{*}{ Facing psychological and mental tension } & Working in difficult conditions \\
\hline & Lack of personal protective equipment \\
\hline & Feeling rejected \\
\hline \multirow{3}{*}{ Creating a context of support } & Proper intradepartmental management \\
\hline & Support of the authorities \\
\hline & Effective communication skills \\
\hline \multirow{4}{*}{ Experiencing personal-professional growth } & Improved learning \\
\hline & \\
\hline & Perception of positive feelings at the end of a crisis \\
\hline & Self-transformation \\
\hline
\end{tabular}

